\title{
The Basomedial Hypothalamus Modulates the Ventilatory Response to Hypoxia in Neonatal Rats
}

\author{
ISMAIL A. DRESHAJ, MUSA A. HAXHIU, RICHARD J. MARTIN, AND JOHN K. YOUNG \\ Department of Pediatrics, Rainbow Babies and Children's Hospital, Case Western Reserve University, \\ Cleveland, Ohio, U.S.A. [I.A.D., M.A.H., R.J.M.]; Department of Physiology, Howard University \\ Specialized Neuroscience Research Program [M.A.H.], Department of Anatomy [J.K.Y.], Howard \\ University College of Medicine, Washington, D.C., U.S.A.
}

\section{ABSTRACT}

\begin{abstract}
We sought to examine the role of the basomedial hypothalamus in the regulation of breathing in neonatal rats. Small basomedial hypothalamic lesions were produced by a lesioning agent, goldthioglucose, in 5-d-old male rat pups, and $2 \mathrm{~d}$ later, baseline ventilation and the ventilatory responses to hypoxia and hypercapnia were examined. When compared with vehicleinjected controls, goldthioglucose-lesioned rat pups had a significantly slower respiratory rate and longer expiratory time at baseline. Lesioned rats displayed an impaired increase in breathing frequency in response to hypoxia, and augmented increases in tidal volume and respiratory drive (the ratio of tidal volume to inspiratory time) during hypoxia relative to controls. Hypercapnic responses were not affected. These data demonstrate that cells
\end{abstract}

in a restricted area of the hypothalamus specifically influence the respiratory response to hypoxia. (Pediatr Res 53: 945-949, 2003)
GTG, goldthioglucose

\section{Abbreviations}
NPY, neuropeptide Y
PVN, paraventricular nucleus of the hypothalamus
$\mathbf{T}_{\mathbf{E}}$, expiratory duration
$\mathbf{T}_{\mathbf{I}}$, inspiratory duration
$\mathbf{T}_{\text {TOT }}$, length of respiratory cycle
$\mathbf{V}_{\mathrm{T}}$, tidal volume

It is well established that ventilatory responses to hypoxia are mediated by discrete neural pathways involving peripheral chemoreceptors, primary afferents, and brainstem respiratoryrelated neurons. The characteristics of the response, however, depend on complex interactions at multiple levels of the neuraxis, including suprapontine structures. Several studies have suggested that the caudal hypothalamus modulates responses to hypoxia and hypercapnia $(1,2)$. For example, one study showed that $21 \%$ of hypothalamic units are activated by hypoxia and $31 \%$ by hypercapnic loading (3). Furthermore, hypoxia and hypercapnia stimulate neurons in various hypothalamic nuclei (paraventricular, supraoptic, and dorsomedial) to synthesize the transcription-regulating protein Fos (4-6). Binding of the adipocyte hormone leptin to receptors in either the hypothalamus or area postrema modulates respiration and may underlie the respiratory abnormalities observed in genetically obese rodents (7-9). Finally, electrolytic lesions that

Received March 22, 2002; accepted November 21, 2002.

Correspondence: M.A. Haxhiu, Department of Physiology, Howard University Specialized Neuroscience Research Program, College of Medicine, 520 W St., NW, Washington, DC 20059, U.S.A.; e-mail: mah10@cwru.edu

Supported by National Institutes of Health grants 1 U54 NS39407 (M.A.H.), HL 50527 (M.A.H.), and HL 62527 (R.J.M.).

DOI: 10.1203/01.PDR.0000064584.67771.82 destroy extensive amounts of perifornical cells in the posterior hypothalamus enhance the ventilatory response to hypoxia (10). However, the role of these structures in regulating ventilatory responses to chemical drive is not well understood.

Functional effects of relatively large electrolytic lesions of the hypothalamus are instructive, but are less helpful in pinpointing the precise location of hypothalamic cells critical for respiratory control. Likewise, unit recording or examination of Fos expression throughout the hypothalamus during hypoxia does not identify cells initiating a hypothalamic response to hypoxia because of multisynaptic projections among activated neuronal pools. These techniques also do not determine the functional role of hypothalamic cells in the regulation of respiratory responses to changes in chemical drive. One approach to this problem is to examine the effects of relatively restricted hypothalamic damage. This can be achieved via the systemic administration of a toxin, GTG, which diffuses into the hypothalamus via the permeable capillaries of the median eminence and which damages only the dorsal portion of the arcuate nucleus and a small portion of the ventromedial hypothalamic nucleus (11).

We hypothesized that the arcuate nucleus of the hypothalamus may be an important regulator of respiratory control. Arcuate neurons immunoreactive for NPY, proopiomelanocor- 
tin, and substance $\mathrm{P}$ project to diverse regions of the hypothalamus such as the PVN. The PVN, in turn, regulates respiratory drive (12). Also, arcuate neurons project directly to the dorsal medulla, an area that strongly influences the activity of respiration-regulating neurons of the medullary pre-Bötzinger complex (13-16). Finally, the arcuate nucleus contains numerous leptin-responsive neurons, and hence may be a major site of the influence of leptin upon respiratory control $(7,9)$.

\section{METHODS}

In this study, 5-d-old Sprague Dawley albino rat pups, weighing about $15 \mathrm{~g}$, were injected intraperitoneally with either saline or with GTG $(0.3 \mathrm{mg} / \mathrm{g}$ in sterile saline). Two days later, ventilatory responses to hypoxia $\left(8 \% \mathrm{O}_{2}, 92 \% \mathrm{~N}_{2}\right)$, were tested. The responses were measured using plethysmography for unrestrained, unanesthetized small rodents (Buxco Electronics, Troy, NY, U.S.A.), which is a modification of the body-box technique (15). Briefly, in the body-box technique, pressure changes caused by differences in the temperature of inhaled or exhaled air are sensed by a sensitive pressure transducer and recorded as a pressure curve. However, in a Buxco plethysmograph, because the box is open to the atmosphere, pressure changes are differential and the recorded curve is a flow curve. With appropriate software, recorded flow is integrated on a breath-by-breath basis to obtain $\mathrm{V}_{\mathrm{T}}$ as well as $\mathrm{T}_{\mathrm{I}}, \mathrm{T}_{\mathrm{E}}$, and $\mathrm{T}_{\text {TOT }}\left(\mathrm{T}_{\mathrm{TOT}}=\mathrm{T}_{\mathrm{I}}+\mathrm{T}_{\mathrm{E}}\right)$.

The temperature in the plethysmograph was kept at $\sim 33^{\circ} \mathrm{C}$ to minimize body heat loss in these small, immature rats. Body temperatures of five vehicle-treated and five GTG-treated rats were also measured before and after hypoxia with an esophageal probe to rule out any possible effects of GTG upon body temperature maintenance that could influence the outcome of the study. To prevent $\mathrm{CO}_{2}$ buildup and a decrease in oxygen, a bias flow of room air $(2 \mathrm{~L} / \mathrm{min})$ continuously passed through the plethysmograph. During exposure to hypoxia, a hypoxic gas mixture was introduced through the bias flow port after the animal was placed in the plethysmograph. Breathing activity was observed until a stable pattern was noted and recorded as baseline ventilatory activity. Then, the hypoxic mixture $(8 \%$ $\mathrm{O}_{2}, 92 \% \mathrm{~N}_{2}$ ) was introduced for $10 \mathrm{~min}$.

Rats were subsequently ( $2 \mathrm{~h}$ later) exposed to $10 \mathrm{~min}$ of hypercapnia $\left(5 \% \mathrm{CO}_{2}, 30 \% \mathrm{O}_{2}, 65 \% \mathrm{~N}_{2}\right)$. To derive ventilatory variables from the plethysmographic recordings, measurements for 20 breaths for each time point and each animal were averaged (20 breaths occurred over a time span no greater than $10 \mathrm{~s})$. This approach allowed us to minimize between-breath variability when analyzing these data. Comparison of baseline ventilatory variables was made via an unpaired $t$ test. Hypoxic responses between groups were compared by two-way ANOVA with repeated measurements. Data are expressed as mean \pm SE. A $p$ value of $<0.05$ was considered statistically significant.

At the end of the experiment, five animals from the GTGtreated group and five of the control pups were deeply anesthetized (pentobarbital, $60 \mathrm{mg} / \mathrm{kg}$ ) and wash-perfused with saline through the left ventricle followed by $10 \%$ formalin. Entire brains were immersed in $20 \%$ sucrose-formalin for cryoprotection and then serial, coronal frozen sections $(30 \mu$ thick) of the hypothalamus and area postrema region were prepared using a sliding microtome. Brain sections were dried down onto subbed slides, stained with $0.1 \%$ thionin in acetate buffer, and inspected for GTG-induced lesions (11). All procedures for handling animals were approved by the Case Western University Institutional Animal Care and Use Committee.

\section{RESULTS}

Hypothalamic sections of brains from GTG-injected rats showed bilateral areas of necrosis, gliosis, and vascular damage that encroached upon the dorsal portion of the arcuate nucleus and ventral margin of the ventromedial nucleus, a pattern that is typical of GTG-induced damage (11). The GTG-induced lesion caused a partial collapse of affected tissue into a glial scar, resulting in a folding and distortion of the normally smooth contours of the adjacent ependymal layer enclosing the third ventricle (Fig. 1). Close inspection of the region bordering the area postrema of these rats, in contrast, revealed no signs of damage, which is consistent with previous

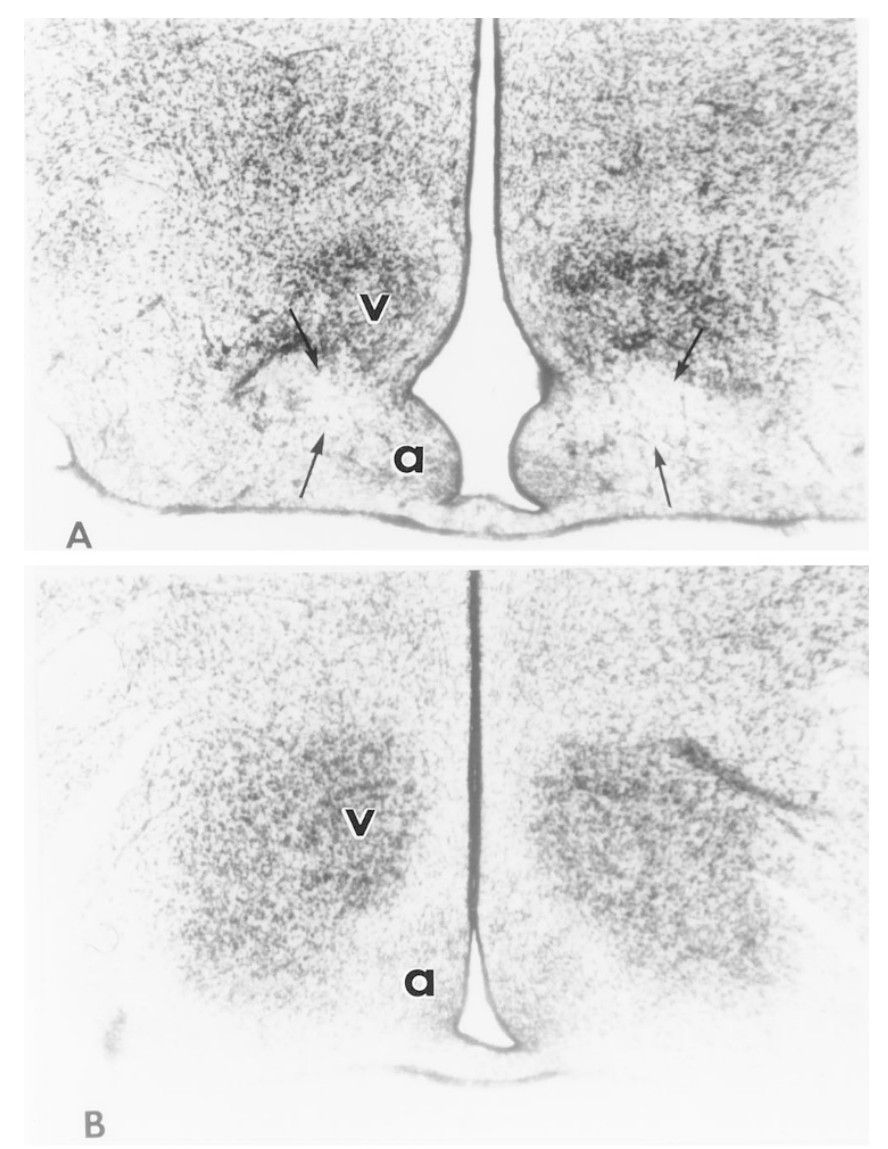

Figure 1. (A) Basomedial hypothalamus from a rat treated with GTG. GTG-induced damage was visible as pale-staining regions of gliosis (arrows) accompanied by focal accumulations of damaged blood vessels. Loss of neurons in portions of both the arcuate $(a)$ and ventromedial $(n)$ nuclei resulted in a partial collapse of the region and a folding and distortion of the normally smooth contours of the ependymal layer enclosing the third ventricle. $(B)$ Hypothalamus from a saline-treated rat, demonstrating the normal structures at these sites. Scale bar $=200 \mu \mathrm{m}$. 
results showing that this dose of GTG is less likely to affect other circumventricular regions as compared with the hypothalamus itself (11). Likewise, inspection of the dorsal portions of brain sections just anterior to the arcuate nucleus revealed no GTG-induced damage in the region of the subfornical organ. No histologic changes in hypothalamic structures were observed in saline-injected groups.

Table 1. Baseline respiratory variables in the two groups of rat pups

\begin{tabular}{lccc}
\hline \multicolumn{1}{c}{ Respiratory parameter } & Vehicle & GTG & $\begin{array}{c}p \text { Value } \\
\text { (unpaired } t \text { test) }\end{array}$ \\
\hline TI, msec & $122 \pm 4$ & $132 \pm 6$ & 0.15 \\
TE, msec & $295 \pm 15$ & $364 \pm 23$ & 0.02 \\
Frequency, breaths/min & $147 \pm 6$ & $126 \pm 7$ & 0.03 \\
VT, $\mu \mathrm{L}$ & $80 \pm 4$ & $80 \pm 3$ & 0.95 \\
Minute ventilation, $\mathrm{mL} / \mathrm{min}$ & $12 \pm 0.8$ & $10 \pm 0.6$ & 0.08 \\
VT/TI, $\mu \mathrm{L} / \mathrm{msec}$ & $0.66 \pm 0.04$ & $0.61 \pm 0.03$ & 0.06 \\
\hline
\end{tabular}
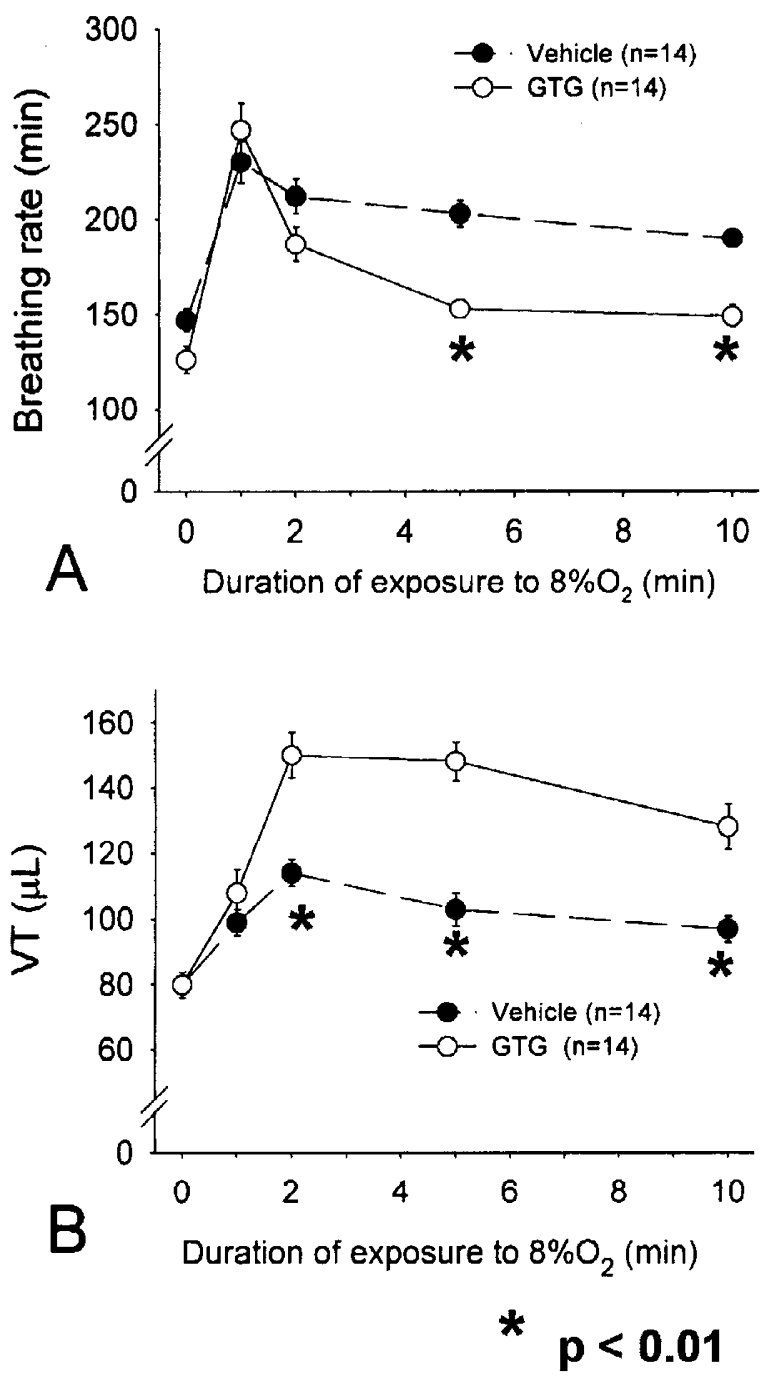

No significant between-group differences in body temperatures were found $(p=0.7)$. In vehicle-treated rats, body temperature before and after hypoxia equaled $35.6^{\circ} \mathrm{C}$ and $35.3^{\circ} \mathrm{C}$, respectively, resulting in a nonsignificant fall in temperature of $0.3^{\circ} \mathrm{C}$. In GTG-treated rats, body temperature before and after hypoxia was $35.5^{\circ} \mathrm{C}$ and $35.2^{\circ} \mathrm{C}$, respectively, also amounting to a fall in body temperature of $0.3^{\circ} \mathrm{C}$.

Baseline respiratory variables of the two groups are summarized in Table 1. Baseline breathing frequency in GTG-treated rats $(n=14)$ was significantly lower than in vehicle-treated animals $(n=14)$. This was associated with a significantly longer baseline $T_{E}$ in the GTG-treated pups (Table 1). As shown in Table 1, there were no other significant differences in baseline ventilatory variables between groups. After exposure to hypoxia, the GTG-treated animals had a response of breathing rate significantly different from the vehicle-treated group, manifested by greater roll-off of frequency $(p<0.01$, two-way ANOVA, Fig. 2A). There were significantly different responses of both inspiratory and expiratory times to hypoxia between
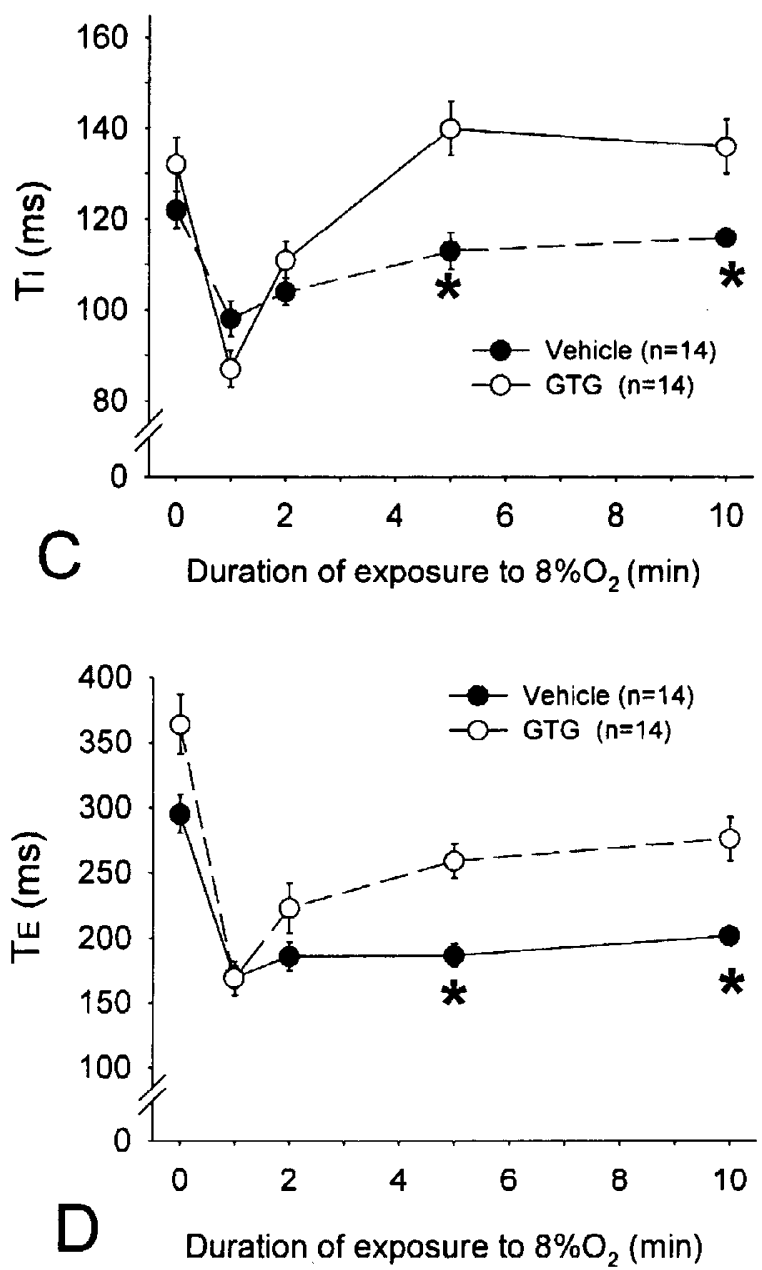

Figure 2. (A) Exposure to $8 \% \mathrm{O}_{2}$ resulted in significantly greater depression in breathing rate in GTG-treated rats when compared with controls. $(B)$ At baseline, VT did not differ between groups, however, during exposure to hypoxia, VT increased significantly more in GTG-treated pups compared with control pups. (C) $\mathrm{T}_{\mathrm{I}}$ initially shortened in both GTG-treated and control groups with the introduction of hypoxia. However, during hypoxic exposure, $\mathrm{T}_{\mathrm{I}}$ of GTG-treated pups rose significantly more than in control pups. $(D)$ Exposure to hypoxia caused a similar shortening of $\mathrm{T}_{\mathrm{E}}$ in both groups. Subsequently, $\mathrm{T}_{\mathrm{E}}$ showed significantly greater prolongation in GTG-treated pups vs controls. 
groups, with less shortening of both $T_{I}$ and $T_{E}$ in GTG-treated pups during the course of hypoxic exposure $\left(p<0.02\right.$ for $\mathrm{T}_{\mathrm{I}}$ and $p<0.01$ for $\mathrm{T}_{\mathrm{E}}$, both two-way ANOVA, Fig. 2, $C$ and $D$ ).

Although baseline values of $\mathrm{V}_{\mathrm{T}}$ were comparable between groups, there was a significantly greater response of $\mathrm{V}_{\mathrm{T}}$ to hypoxia in the GTG-treated rat pups ( $p<0.001$, two-way ANOVA, Fig. 2B). Also, GTG lesions enhanced the hyperpneic increase in $\mathrm{V}_{\mathrm{T}}$ at $2 \mathrm{~min}$ of hypoxia, although other respiratory variables at this time did not differ between groups $(p<0.01)$. In addition, in spite of greater prolongation of $\mathrm{T}_{\mathrm{I}}$, the $\mathrm{V}_{\mathrm{T}} / \mathrm{T}_{\mathrm{I}}$ ratio, an index of respiratory drive, was significantly greater in the GTG group during hypoxia than in control animals $(p<0.01$, Fig. $3 A)$. Finally, the percentage change in Vт times frequency (minute ventilation) was significantly greater in the GTG-treated rats than in the vehicle-treated rats during exposure to $8 \%$ oxygen $(p<0.001$, Fig. $3 B$ ). However, there was no difference between groups in the roll-off of the VT response to hypoxia.

No significant differences were observed between groups in response to hypercapnic loading (data not shown).

\section{DISCUSSION}

It is widely accepted that hypoxic exposure during early postnatal life results in a biphasic ventilatory response characterized by an initial increase and a subsequent gradual decrease in ventilation. Therefore, the current results are in agreement with previously published data in newborn animals and in preterm infants (14-17). However, the data from the present study show for the first time that GTG-induced hypothalamic lesions affect not only baseline respiratory timing variables, but also the profile of the ventilatory response to hypoxia. Lesioned rats displayed a greater depression of respiratory timing in response to hypoxia. However, their augmented $V_{\text {T }}$ response led to an increase in ventilation in spite of a reduced breathing frequency. These data suggest that neurons within the basomedial hypothalamus activate a neuronal network that shortens inspiratory and expiratory time in response to hypoxia.

The greater depression of respiratory frequency in response to hypoxia in the lesioned pups mimics what we see in preterm babies (15). It is known from fetal and neonatal sheep experiments that descending inhibition to the medulla contributes to this phenomenon $(18,19)$. The current data support the assumption that there are also excitatory inputs from the basomedial hypothalamus to the brainstem. Maturational changes in these neurons may contribute to age differences in hypoxic depression.

In GTG-treated rats, exposure to hypoxic stress induced a larger increase in $\mathrm{V}_{\mathrm{T}}$ than in the control group. During the first 2 min of hypoxia, this was unaccompanied by any other changes in respiratory variables. Subsequently, there was also a disproportionate lengthening of inspiratory duration in GTGlesioned rats. These data show that the hypothalamic arcuate nucleus provides input to the brainstem respiratory-related network that regulates the gain of the ventilatory response to hypoxia. Such a network optimizes gas exchange at a minimal level of respiratory effort (work).
The mechanism of GTG lesion formation seems to involve localized diffusion of GTG from the median eminence and uptake of GTG into specialized astrocytes that possess highcapacity glucose transporter proteins $(11,20)$. After uptake into target cells, toxic effects of the GTG molecule seem to cause a generalized cell death of glial, neural, and vascular elements in the region of the lesion.

Because arcuate neurons have been found to directly project to the medulla, one plausible explanation for the observed effects of lesions was the destruction of these specific arcuate cells (14). Alternatively, destruction of arcuate neurons that project to the PVN or lateral regions of the hypothalamus could also affect respiration, because these sites also project to the medulla $(12,14)$.

A variety of subpopulations of arcuate neurons, each containing specific neurotransmitters, could contribute to the effects of lesions. Arcuate neurons containing substance P, for example, could be involved, because substance $\mathrm{P}$ affects respi-
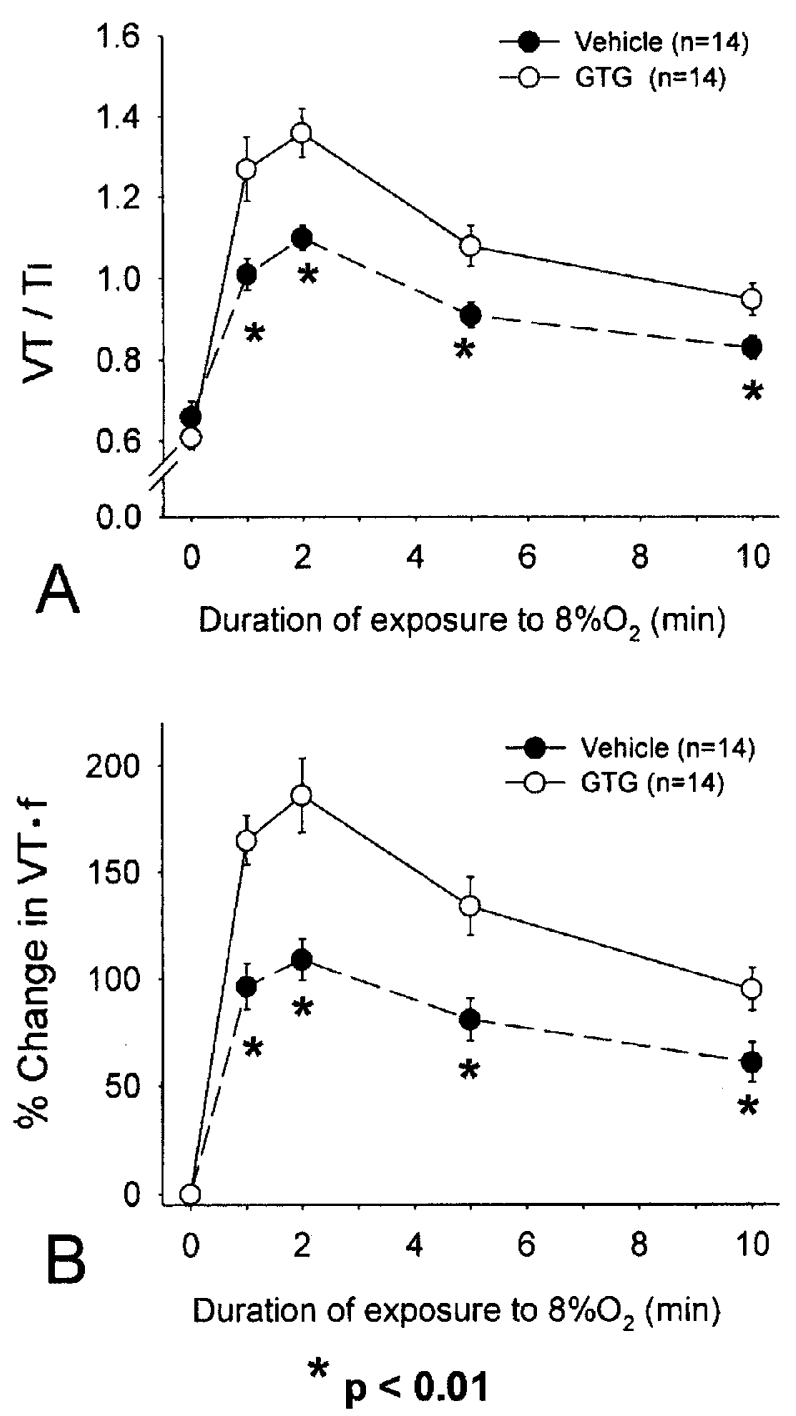

Figure 3. (A) $\mathrm{The} \mathrm{V}_{\mathrm{T}} / \mathrm{T}_{\mathrm{I}}$ ratio, an index of respiratory drive, was similar in both groups during room air breathing. Exposure to hypoxia caused a significantly greater increase in $\mathrm{VT}_{\mathrm{T}} \mathrm{T}_{\mathrm{I}}$ in GTG-treated pups compared with control pups. $(B)$ Percentage changes in minute ventilation during hypoxia were greater in GTG-treated pups compared with control pups. 
ratory motor output and breathing frequency, probably via an action upon the pre-Bötzinger complex (21). Also, lesions may affect neurons that contain NPY and project to the PVN. Hence, a lesion-induced change in function of NPY arcuate neurons and a withdrawal of excitatory inputs to PVN neurons that project both to the pre-Bötzinger complex and to phrenic nuclei could explain these results (12).

In accord with this general hypothesis, one study reported an increase in the mRNA for NPY after GTG lesioning (22). Other studies, however, have not replicated these findings, suggesting that other populations of arcuate neurons are responsible for lesion-induced functional changes (23-25). Thus, the exact roles of various arcuate neurotransmitters in lesioninduced hypothalamic dysfunction and changes in the ventilatory response to hypoxia await clarification.

Yet another possible explanation for functional effects of arcuate lesions is an interruption of fibers passing from the arcuate nucleus to the lateral hypothalamus. Fibers from NPYcontaining arcuate neurons innervate orexin-immunoreactive neurons in the lateral hypothalamus, which in turn project to many brainstem regions regulating respiration and which also project back to arcuate NPY neurons $(26,27)$.

Based upon these data, it is possible that a maturation of hypothalamic circuits could contribute to changes in respiratory regulation that occur during the first week of development of the rat (28). It is known that levels of arcuate neurotransmitters do not reach adult levels until several weeks after birth (29). Also, axonal projections from arcuate neurons to the nearby median eminence become complete only during the last several days of development in utero; completion of projections to more distant structures like the medulla are likely completed postnatally (30).

The question of whether or not hypothalamic neurons themselves monitor blood levels of oxygen during hypoxia, either directly or via indirect input from peripheral chemoreceptive cells, is also germane to this study and could not be directly addressed using these methods. Hypothalamic neurons could either directly monitor oxygen levels or else simply modulate the activity of oxygen-sensitive neurons located elsewhere. Evidence for both viewpoints has been reviewed in a number of studies $(3,4)$.

The ventilatory changes reported here are somewhat analogous to those found after electrolytic lesions of the posterior hypothalamus (10). In that study, $\dot{\mathrm{V}}_{\mathrm{E}}\left(\mathrm{V}_{\mathrm{T}} \times\right.$ breathing rate) was increased in lesioned rats by about $17 \%$ during hypoxia. In our study, $\dot{V}_{\text {E }}$ overall was also increased. The considerably smaller hypothalamic lesions produced in our study thus had an effect upon respiration comparable to larger electrolytic lesions.

Finally, we speculate that alterations in diencephalic neuronal circuits may contribute to a number of clinical syndromes involving the hypothalamus that may manifest simultaneous abnormalities in appetite, body weight, sleep, and respiratory control during sleep $(9,31,32)$.

\section{REFERENCES}

1. Horn EM, Waldrop TG 1994 Modulation of the respiratory responses to hypoxia and hypercapnia by synaptic input onto caudal hypothalamic neurons. Brain Res $664: 25-33$
2. Horn EM, Dillon GH, Fan Y-P, Waldrop TG 1999 Developmental aspects and mechanisms of rat caudal hypothalamic neuronal responses to hypoxia. J Neurophysiol 81:1949-1959

3. Dillon GH, Waldrop TG 1993 Responses of feline caudal hypothalamic cardiorespiratory neurons in hypoxia and hypercapnia. Exp Brain Res 96:260-272

4. Berquin P, Bodineau L, Gros F, Larnicol N 2000 Brainstem and hypothalamic areas involved in respiratory chemoreflexes: a Fos study in adult rats. Brain Res 857:30-40

5. Haxhiu MA, Yung K, Erokwu B, Cherniack NS $1996 \mathrm{CO}_{2}$-induced c-fos expression in the CNS catecholaminergic neurons. Respir Physiol 105:35-45

6. Nitsos I, Walker DW 1999 The distribution of FOS-immunoreactive neurons in the brainstem, midbrain and diencephalon of fetal sheep in response to acute hypoxia in mid and late gestation. Dev Brain Res 114:9-26

7. Baskin DG, Hahn TM, Schwartz MW 1999 Leptin sensitive neurons in the hypothalamus. Horm Metab Res 31:345-350

8. Mercer JG, Moar KM, Hoggard N 1998 Localization of leptin receptor (Ob-R) messenger ribonucleic acid in the rodent hindbrain. Endocrinology 139:29-34

9. O'Donnell CP, Tankersley CG, Polotsky VP, Schwartz AR, Smith, PL 2000 Leptin, obesity, and respiratory function. Respir Physiol 119:163-170

10. Hinrichsen CFL, Maskrey M, Mortola JP 1998 Ventilatory and metabolic responses to cold and hypoxia in conscious rats with discrete hypothalamic lesions. Respir Physiol 111:247-256

11. Young JK 1989 The glial drug methionine sulfoximine reduces goldthioglucose lesions in mice. Brain Res Bull 24:929-936

12. Yeh ER, Erokwu B, LaManna JC, Haxhiu MA 1997 The paraventricular nucleus of the hypothalamus influences respiratory timing and activity in the rat. Neurosci Lett 232:63-66

13. Smith JC, Ellenberger HH, Ballanyi K, Richter DW, Feldman JL 1991 Pre-Botzinger complex: a brainstem region that may generate respiratory rhythm in mammals. Science 254:726-729

14. Schwanzel-Fukuda M, Morrell JI, Pfaff DW 1984 Localization of forebrain neurons which project directly to the medulla and spinal cord of the rat by retrograde tracing with wheat germ agglutinin. J Comp Neurol 226:1-20

15. Martin RJ, DiFiore JM, Jana L, Davis RL, Miller MJ, Coles SK, Dick TE 1998 Persistence of the biphasic ventilatory response to hypoxia in preterm infants. J Pediatr 132:960-964

16. Miller MJ, Haxhiu MA, Haxhiu-Poskurica B, Dreshaj IA, DiFiore JM, Martin RJ 2000 Recurrent hypoxic exposure and reflex responses during development in the piglet. Respir Physiol 123:51-61

17. Suguihara C, Bancalari E, Hehre D, Duara S, Gerhardt T 1994 Changes in ventilation and oxygen consumption during acute hypoxia in sedated newborn piglets. Pediatr Res 35:536-540

18. Dawes GS, Gardner WN, Johnston BM, Walker DW 1983 Breathing in fetal lambs: the effect of brain stem section. J Physiol 335:535-553

19. Gluckman PD, Johnston BM 1987 Lesions in the upper lateral pons abolish the hypoxic depression of breathing in unanaesthetized fetal lambs in utero. J Physiol 382:373-383

20. Leloup C, Arluison M, Lepetit N, Cartier N, Marfaing-Jallat P, Ferre P, Penicaud L 1994 Glucose transporter 2 (Glut 2): expression in specific brain nuclei. Brain Res 638:221-236

21. Haxhiu MA, Cherniack NS, van Lunteren E 1990 Central action of tachykinins on activity of expiratory pumping muscles. J Appl Physiol 69:1981-1986

22. Young JK, McKenzie JC, Brady LS, Herkenham M 1994 Hypothalamic lesions increase levels of neuropeptide Y mRNA in the arcuate nucleus of mice. Neuroscience Lett 165:13-17

23. Bergen HT, Mizuno TM, Taylor J, Mobbs CV 1998 Hyperphagia and weight gain after gold-thioglucose: relation to hypothalamic neuropeptide $\mathrm{Y}$ and proopiomelanocortin. Endocrinology 139:4483-4488

24. Marks JL, Waite K, Cameron-Smith D, Blair SC, Cooney GJ 1996 Effects of goldthioglucose on neuropeptide Y messenger RNA levels in the mouse hypothalamus. Am J Physiol 270:R1208-R1214

25. Desjardins CG, Brawer JR, Beaudet A 1993 Estradiol is selectively neurotoxic to hypothalamic $\beta$-endorphin neurons. Endocrinology 132:86-93

26. Harrison TA, Chen CT, Dun NJ, Chang JK 1999 Hypothalamic orexin A-immunoreactive neurons project to the rat dorsal medulla. Neurosci Lett 273:17-20

27. Horvath TL, Diano S, van den Pol AN 1999 Synaptic interaction between hypocretin (orexin) and neuropeptide $\mathrm{Y}$ cells in the rodent and primate hypothalamus: a novel circuit implicated in metabolic and endocrine regulation. J Neurosci 19:1072-1087

28. Abu-Shaweesh JM, Dreshaj IA, Thomas AJ, Haxhiu MA, Strohl KP, Martin RJ 1999 Changes in respiratory timing induced by hypercapnia in maturing rats. J Appl Physiol 87:484-490

29. Jansson JO, Ishikawa K, Katakami H, Frohman LA 1987 Pre- and postnatal developmental changes in hypothalamic content of rat growth hormone-releasing factor. Endocrinology 120:525-530

30. Makarenko IG, Ugrumov MV, Calas A 2001 Axonal projections from the hypothalamus to the median eminence in rats during ontogenesis: DiI tracing study. Anat Embryol (Berl) 204:239-252

31. Lavie P, Klein E, Gadoth N, Bental E, Zomer J, Bechar M, Wajsbort J 1981 Further observations on sleep abnormalities in Kleine-Levin syndrome: abnormal breathing pattern during sleep. Electroencephalogr Clin Neurophysiol 52:98-101

32. Lindgren AC, Hellstrom LG, Ritzen Em, Milerad J 1999 Growth hormone treatment increases $\mathrm{CO}(2)$ response, ventilation and central inspiratory drive in children with Prader-Willi syndrome. Eur J Pediatr 158:936-940 